\title{
Acceptability of Mobile Phone Technology for Medication Adherence Interventions among HIV-Positive Patients at an Urban Clinic
}

\author{
Christopher W. T. Miller and Seth Himelhoch \\ Department of Psychiatry, University of Maryland School of Medicine, 737 West Lombard Street, Room 516, Baltimore, MD 21201, USA
}

Correspondence should be addressed to Christopher W. T. Miller; chmiller@psych.umaryland.edu

Received 29 March 2013; Accepted 11 July 2013

Academic Editor: Gregory Kirk

Copyright (c) 2013 C. W. T. Miller and S. Himelhoch. This is an open access article distributed under the Creative Commons Attribution License, which permits unrestricted use, distribution, and reproduction in any medium, provided the original work is properly cited.

\begin{abstract}
Mobile phone technology is increasingly used to overcome traditional barriers limiting access to care. The goal of this study was to evaluate access and willingness to use smart and mobile phone technology for promoting adherence among people attending an urban HIV clinic. One hundred consecutive HIV-positive patients attending an urban HIV outpatient clinic were surveyed. The questionnaire evaluated access to and utilization of mobile phones and willingness to use them to enhance adherence to HIV medication. The survey also included the CASE adherence index as a measure of adherence. The average age was $46.4(\mathrm{SD}=9.2)$. The majority of participants were males (63\%), black (93\%), and Hispanic (11.4\%) and reported earning less than $\$ 10,000$ per year (67.3\%). Most identified themselves as being current smokers (57\%). The vast majority reported currently taking HAART (83.5\%). Approximately half of the participants reported some difficulty with adherence (CASE $<10)$. Ninety-six percent reported owning a mobile phone. Among owners of mobile phones $47.4 \%$ reported currently owning more than one device. Over a quarter reported owning a smartphone. About $60 \%$ used their phones for texting and 1/3 used their phone to search the Internet. Nearly $70 \%$ reported that they would use a mobile device to help with HIV adherence. Those who reported being very likely or likely to use a mobile device to improve adherence were significantly more likely to use their phone daily $(P=0.03)$ and use their phone for text messages $(P=0.002)$. The vast majority of patients in an urban HIV clinic own mobile phones and would use them to enhance adherence interventions to HIV medication.
\end{abstract}

\section{Introduction}

Optimal adherence to HAART strongly predicts HIV viral suppression [1] and is linked to improved survival [2]. Low adherence to HAART in the United States is common with approximately only $50 \%-70 \%$ of prescribed doses taken [3, 4]. One meta-analysis found that those who participated in HAART-related adherence-enhancing interventions were significantly more likely to achieve $95 \%$ adherence and viral load suppression compared to the control condition [5]. A recent systematic review analyzed findings from 31 projects assessing use of SMS (short message service) technology, most for patients with HIV/AIDS in developing countries [6]; the findings pointed towards SMS as a promising and mostly well-accepted intervention strategy for use in healthcare.
The utilization of technology-based health applications for disease prevention and management has been progressively explored and expanded upon [7-11]. Promising results have been found for a number of conditions (e.g., diabetes mellitus, asthma, nicotine use, and obesity) with use of mobile phone technology $[12,13]$ as well as more specifically with text messaging $[14,15]$. This extends to people living with HIV (PLWH), and the utilization of technology in improving education, adherence, and biological markers (CD4 count and viral load) has shown promising results [1618]. As mobile technology access has become increasingly widespread, this seems to be an ideal tool to reach a large segment of PLWH in a cost-effective manner [19]. Thus far, technologies employed with this population have included computer-based programs [20,21], mobile devices (both for phone counseling sessions [22-24] as well as text messaging) 
[16-18, 25, 26], and paging devices [27]. These have been used as educational resources and as reminders for taking HAART, in an effort to improve disease control.

As mobile technology evolves, many people are updating their devices to smartphones, which offer a greater number of features and may allow for more creative and interactive interventions for improving adherence in PLWH. Ability and willingness to utilize this technology are key factors in ensuring the success of planned intervention strategies. This study aimed to evaluate access and willingness to use smart and mobile phone technology for promoting adherence among people attending an urban HIV clinic. To our knowledge, this is the first study to specifically address potential incorporation of smartphones in treatment paradigms.

\section{Materials and Methods}

2.1. Study Design and Sample. This single site study sought to evaluate access and willingness to use smart and mobile phone technology for promoting adherence among people attending an urban HIV clinic. Eligibility for the study included having a diagnosis of HIV and attending the clinic on the day of recruitment. Potential participants were recruited in May 2012. One hundred consecutive adult (18 years of age and older) HIV-positive patients attending an urban HIV outpatient clinic were surveyed. All eligible participants on the day of recruitment were given the opportunity to participate in the study. None declined. Everyone enrolled in the study completed the survey. The study was reviewed by the University of Maryland Baltimore's Institutional Review Board and given an exempt status. Participants were paid $\$ 10$ for completing the study survey.

2.2. Assessment Instruments. The study questionnaire evaluated access to and utilization of mobile phones and willingness to use them to enhance adherence to HIV medication. The present study was given an exempt status by the Institutional Review Board (IRB). All patient data was de-identified, and confidentiality was thus preserved. All study procedures occurred behind a locked, closed door.

The questionnaire included the following sections.

Demographic Questionnaire. Standardized questions were used to gather demographic information including age, gender, race, education, job description, employment history, and smoking status.

Ownership, Access, and Willingness to Use Mobile or Smartphone Devices. Questions were created de novo or adapted from that questions that were developed by the Pew Research Center, Pew Internet and American Life Project, to evaluate use of mobile and smartphone devices. Questions regarding ownership (including number of phones, types of phones, and service plan utilized); access (e.g., internet); utilization (including utilization of text messaging, phone calling, software applications, and social network sites), and willingness to use mobile devices to access and enhance medical care were employed.
The Pew questionnaire assessed the following categories of cell phone use: (1) take a picture; (2) send or receive text messages; (3) access the internet; (4) send or receive email; (5) record Video; (6) download applications; (7) look for health or medical information online; and (8) check bank account balance or do any online banking. These categories were stratified in the Pew questionnaire according to the following demographic data: gender, age, race/ethnicity, annual household income, and education level. The Results section will outline the modifications to the questionnaire that were utilized in the present study.

Center for Adherence Support Evaluation (CASE) Adherence Index [28]. The CASE index is a 3-item adherence questionnaire. The three self-reported measures of adherence are as follows: A1-frequency of "difficulty taking HIV medications on time" (no more than two hours before or two hours after the time the patient's doctor instructed to take the medication); A2 - "average number of days per week at least one dose of HIV medications was missed"; and A3- "last time missed at least one dose of HIV medications." With regards to scoring, A1 contributes a possible range of one to four points, while A2 and A3 each contributes one to six points. A score of greater than 10 is associated with good adherence. A score of 10 or less is associated with poor adherence. For those who reported missing a dose of HAART medication on the CASE adherence index were asked questions about the reasons for which they missed taking medications from the AACTG Adherence Instrument [29]. The AACTG Adherence Instrument includes 11 reasons a person may not have taken HIV medication. Questions are rated on a 4-point likert scale (never, rarely, sometimes, and often).

2.3. Analysis. Univariate distributions included percentages for dichotomous variables and means for normally distributed continuous variables. Comparison of means was made using two-sided $t$-tests, while comparison of percentages was made using the chi-square of Fischers exact method. Data was analyzed using SAS. All reported $P$ values are twosided.

\section{Results}

3.1. Participant Characteristics. The average age was 46.4 years $(\mathrm{SD}=9.2)$. The majority of participants were males (62.6\%), black (93.0\%), and Hispanic $(11.4 \%(n=9))$ and reported earning less than $\$ 10,000$ per year (67.3\%). Most identified themselves as being current smokers (57\%). The vast majority reported currently taking HAART (83.5\%) (see Table 1).

3.2. Ownership and Utilization of Mobile Phones. Ninetysix percent $(n=100)$ reported owning a mobile phone. Among owners of mobile phones $47.4 \%$ reported currently owning more than one device, $75 \%$ reported using it for one year or more, and $81 \%$ report using it 5-7 days a week. Forty-two percent reported having a phone plan without 
TABLE 1: Demographic characteristics of study sample.

\begin{tabular}{lc}
\hline Demographic characteristic & \\
\hline Age $($ mean \pm SD) & $46.4 \pm 9.2$ \\
Gender $(n=99)$ & \\
$\quad$ Male & $62.6 \%$ \\
Race $(n=99)$ & \\
$\quad$ Black & $93.0 \%$ \\
$\quad$ White & $4.0 \%$ \\
$\quad$ Other & $3.0 \%$ \\
Ethnicity $(n=79)$ & \\
$\quad$ Hispanic & $11.4 \%$ \\
Education $(n=99)$ & \\
$\quad<$ High school & $36.3 \%$ \\
$\quad$ High school/GED & $37.4 \%$ \\
$\quad>$ High school & $26.3 \%$ \\
Income $(\$ /$ year $)(n=99)$ & \\
$\quad<10,000$ & $67.3 \%$ \\
10,000-30,000 & $23.5 \%$ \\
$\quad>30,000$ & $9.2 \%$ \\
Taking HAART $(n=99)$ & $83.5 \%$ \\
Current smoker $(n=98)$ & $57 \%$ \\
\hline
\end{tabular}

TABLE 2: Reasons given for using their cell phone.

\begin{tabular}{ll}
\hline Reasons $(n=96)$ & $\%$ \\
\hline Call out or receive phone calls & 92 \\
Camera or video camera & 64 \\
Send or receive text messages & 59 \\
Clock & 49 \\
Calendar/scheduling & 48 \\
Alarms & 47 \\
Calculator & 41 \\
Access the Internet & 34 \\
Listen to music & 32 \\
Send or receive email & 29 \\
\hline
\end{tabular}

a contract and the vast majority report never having to discontinue service because they could not afford it (66\%). Nearly all reported using their cell phone to make telephone calls (92\%). Fifty-nine percent used their phones for texting. Those who report using text messaging were significantly more likely to be younger ( 42.1 years \pm 9.8 versus 51.2 years \pm 7.3 ) compared to those who did not report texting. No other demographic factor was significant in bivariate analysis. Thirty-four percent used their phone to search the Internet. Nearly half used their phone to set alarms (47\%); schedule events using a calendar (48\%); and use the clock (49\%) (see Table 2).

Over a quarter $(28.7 \%)$ reported owning a smartphone. Those who reported owning a smartphone were significantly more likely to be younger ( 39.8 years \pm 8.6 versus $47.3 \pm 11.6$, $t=3.20, P=0.002)$ and more likely to have incomes greater than $\$ 10,000$ per year compared to those with higher incomes
(76.9\% versus $40.7 \%, P=0.03$ ). No other demographic factor was significant in bivariate analysis.

3.3. Adherence to $H A A R T$. Among those reporting taking HAART, approximately half $(51 \%(n=42))$ had poor adherence as evaluated by the Center for Adherence Support Evaluation (CASE) adherence index (i.e., CASE < 10). Bivariate analysis did not demonstrate any significant differences in demographic characteristics comparing those with poor adherence (i.e., CASE < 10) to those with good adherence (i.e., CASE > 10). Among those reporting ever missing a dose of HIV medication $(n=25)$ the most frequent reasons included (1) simply forgetting (52\% reported "sometimes"); (2) sleeping through the dosage (52\% reported "sometimes"); (3) being away from home (39\% reported "sometimes" and $9 \%$ reported "often"); and (4) having a change in daily routine ( $40 \%$ reported "sometimes" and $4 \%$ reported "often") (see Table 3).

All participants were asked how likely they would be to use a cell phone that could remind them every day when to take HIV medication. The vast majority reported (69\%) that they were "likely" or "very likely" to use it. Those who said they were "very likely" or "likely" to use a cell phone to remind them to take medication were significantly more likely to report ever using their phone to receive or send text messages (68.3\% versus $\left.33.3 \%, \chi^{2}=9.97, P<0.002\right)$; more likely to use the phone 7 days a week (71.9\% versus $48.1 \%$, fisher exact test, $P<0.03$ ); and use their phone to set alarms (53.9\% versus $29.7 \%, \chi^{2}=3.47, P<0.04$ ).

\section{Discussion}

The vast majority of patients in an urban HIV clinic own mobile phones and would use them to enhance adherence interventions to HIV medication. In particular we found that nearly all (96\%) of the participants surveyed owned a mobile phone and nearly half (47.4\%) reported currently owning more than one device. Sending or receiving text messaging was the most common additional feature that was used on the mobile devices. Although 58\% reported sending or receiving a text message, this was somewhat less than the $80 \%$ of cell phone owners who are reported nationally to use their cell phone to send or receive a text message [30]. Potential reasons for this discrepancy is that the population studied is on average of an older age and thus may be more used to using landline phones. In addition, the overall education level of the population is low, and this may impact comfort level with regards to typing messages.

Nearly $70 \%$ reported that they would use a mobile device to help with HIV adherence. Those who reported being very likely or likely to use a mobile device to improve adherence were significantly more likely to use their phone daily $(P=$ $0.03)$ and use their phone for text messages $(P=0.002)$. Text messaging has been shown to help with multiple aspects of care in a number of medical conditions (including HIV), with demonstrable improvement in medication adherence and biological markers [18, 31]. A number of studies have addressed how best to employ this instrument in optimizing compliance $[26,32,33]$. Promising results using text 
TABLE 3: Response to the AACTG Adherence Instrument among participants who reported ever missing a dose of HIV medication (expressed in percentages).

\begin{tabular}{|c|c|c|c|c|}
\hline List of reasons $(n=25)$ & Never & Rarely & Sometimes & Often \\
\hline Simply forgot & 8 & 40 & 52 & 0 \\
\hline Fell asleep/slept through dosage & 16 & 32 & 52 & 0 \\
\hline Away from home $(n=23)$ & 30 & 22 & 39 & 9 \\
\hline Had a change in daily routine & 36 & 20 & 40 & 4 \\
\hline Fell ill or sick & 42 & 23 & 31 & 4 \\
\hline Felt depressed/overwhelmed & 52 & 12 & 28 & 8 \\
\hline Did not want others to notice me taking pills & 68 & 8 & 12 & 12 \\
\hline Had too many pills to take & 68 & 8 & 24 & 0 \\
\hline Wanted to avoid side effects & 64 & 16 & 20 & 0 \\
\hline Had problems taking meds at specific time & 48 & 32 & 20 & 0 \\
\hline Felt drug was toxic or harmful & 76 & 12 & 12 & 0 \\
\hline
\end{tabular}

messaging have been found in several studies [16-18, 25, $26,33]$. One of the seminal studies in this area was a multisite randomized controlled trial (RCT) utilizing mobile device technology to improve adherence to highly active antiretroviral therapy (HAART) - the WelTel Kenyal study [33] — in which a single SMS was sent to the participants at the beginning of the week asking, "How are you?" compared to a control group receiving standard care. In terms of adherence, $62 \%$ of the intervention groups participants had greater than 95\% compliance, compared to 50\% compliance in the control group. The intervention group also reported greater viral suppression at 12 months. Another RCT in Kenya reported a statistically significant improvement in HAART adherence at 48 weeks in the group receiving weekly SMS reminders, as compared to the control group [26]. Interestingly, the latter study did not find a significant increase in adherence in the group receiving daily messages.

Individual patient characteristics need to be recognized in order to maximize intervention responses, particularly with regards to patterns of cell phone use. Individuals are more or less comfortable with certain aspects of their cell phones, and this degree of comfort will influence how likely they are to participate in proposed interventions. Sidney et al. conducted a study in which 139 adult HIV patients who were on regular antiretroviral therapy received a weekly interactive call as well as a neutral pictorial SMS [34]. The participants were requested to report what their adherence had been like the previous day; in the case of failure to respond, additional calls to the individual patients were made. In their study, only $11 \%$ of patients preferred only receiving an SMS, while $87 \%$ indicated a preference for the phone call reminder.

It should be noted that participants seemed to have a greater knowledge of the phone-related functions as compared with the SMS (e.g., calendar, alarm, and listening to music). This correlates with the findings in our study and makes logical sense; participants who expressed being more likely to use mobile phone reminders were those who use a greater number of functions on their phones, and use them on a more regular basis. How interactive an intervention is may also be a key component, as the individual may variably feel more or less involved in their own care, depending on the investment the intervention team makes in ensuring they are reading the messages, as opposed to being just a passive recipient of an impersonal reminder. In an RCT performed at a teaching hospital in Boston, $23 \mathrm{HIV}$-positive participants were randomized to either receive a mobile phone message with content selected by the patient from a list of options (e.g., weather report, news, and Bible verses) or to receive a beeper [17]. Participants using the mobile device were encouraged to respond to the reminder (devices would continue to beep until this occurred), whereas the pager would only beep once, irrespective of the participant's response. When using mixed measures of adherence, there was a statistically significant difference between the two groups at both three $(P=0.0129)$ and six weeks $(P=0.002)$, favoring the mobile phone group. Results may have been favored by the fact that there were constant reminders until a response was obtained in the intervention groups; this is important due to possible user fatigue over time-there was a decrease in participants' responses to text messages between weeks three and six of the study. To exemplify further, in the study by Simoni et al., there was no improvement at any point of the intervention in terms of antiretroviral adherence when utilizing a two-way pager system (though there was improvement in biological markers of illness) [27]. One of the potential strategies to assist individuals who do not utilize text messaging would be to offer training in the use of a self-contained mobile application.

Randomized controlled trials (RCTs) which intervened sending individuals text messages on a weekly basis reported significant improvement in adherence $[18,26]$. In the study by da Costa et al. with Brazilian women with HIV/AIDS [25], there was a nonsignificant improvement in medication compliance in the group receiving SMS multiple times during the week, and over $63 \%$ of participants reported that the intervention helped them to take their medications more regularly. Intermittently sending reminders (as opposed to everyday) has been utilized as a way of keeping patients from underestimating the importance of the messages, as well as focusing on days which have been shown to be more strongly associated with noncompliance (e.g., weekends) [25, 35]. 
User fatigue and trivializing of frequent messaging may be hampering factors in maintaining compliance.

In our study, approximately a quarter reported owning a smartphone, which was considerably less than the national smartphone ownership of 52\% reported by the Pew Internet and American Life Project [30]. This difference may be due to the cost associated with owning a smartphone, the additional cost of the data-plan, and possibility of a less robust market penetration of these devices at the time of the study. However, with the increased penetration of smartphone ownership only growing, there is a greater opportunity to harness the utility and multiple applications associated with smartphones.

One limitation to studies of this nature is the potential difficulty in generalizing some of the findings. This has been highlighted by other authors in the past [31], emphasizing the small sample sizes of some of the studies and the limited population being studied $[36,37]$, although there have been robust findings in at least one study with greater power [26]. One particular concern is patient confidentiality, as their personal cell phone may not always be on their person, and access by other people to reminders on the mobile device may be a sensitive issue [25]. This is especially salient given the nature of the illness and the potentially revealing messages that may be sent to patients. On the other hand, some authors have found that the vast majority of patients do not feel that their privacy is being intruded upon [34]. Either way, there are many options which can be utilized to better protect patient privacy (a concern which has been raised before) [38]. Another limitation of the study is that we did not collect information on the total number of missed appointments an individual had up until the start of the study. This information may have improved our understanding of adherence behaviors. Finally, we did not collect information regarding HIV risk factors or biological markers (i.e., viral load or CD4 count) of disease.

\section{Conclusions}

Future directions include incorporation of ever-evolving technology as it becomes increasingly accessible to the general population. PLWH have shown they are open to employ these strategies in the management of their illness [34]. Development of interactive, economically viable options for PLWH has been shown to be a very promising field, which could benefit a significant portion of the HIV/AIDS population. The vast majority of patients in an urban HIV clinic own mobile phones and would use them to enhance adherence interventions to HIV medication. In addition, our study indicates that smartphone use is becoming a reality for this population, which could open new avenues for technology-based interventions, though continued data collection through well-organized RCTs is needed.

\section{References}

[1] D. L. Paterson, S. Swindells, J. Mohr et al., "Adherence to protease inhibitor therapy and outcomes in patients with HIV infection," Annals of Internal Medicine, vol. 133, no. 1, pp. 21-30, 2000 .
[2] F. J. Palella Jr., K. M. Delaney, A. C. Moorman et al., "Declining morbidity and mortality among patients with advanced human immunodeficiency virus infection. HIV Outpatient Study Investigators," The New England Journal of Medicine, vol. 338, no. 13, pp. 853-860, 1998.

[3] D. R. Bangsberg, F. M. Hecht, E. D. Charlebois et al., "Adherence to protease inhibitors, HIV-1 viral load, and development of drug resistance in an indigent population," AIDS, vol. 14, no. 4, pp. 357-366, 2000.

[4] B. D. Heckman, S. L. Catz, T. G. Heckman, J. G. Miller, and S. C. Kalichman, "Adherence to antiretroviral therapy in rural persons living with HIV disease in the United States," AIDS Care, vol. 16, no. 2, pp. 219-230, 2004.

[5] J. M. Simoni, C. R. Pearson, D. W. Pantalone, G. Marks, and N. Crepaz, "Efficacy of interventions in improving highly active antiretroviral therapy adherence and HIV-1 RNA viral load: a meta-analytic review of randomized controlled trials," Journal of Acquired Immune Deficiency Syndromes, vol. 43, supplement 1, pp. S23-S35, 2006.

[6] C. Deglise, L. S. Suggs, and P. Odermatt, "SMS for disease control in developing countries: a systematic review of mobile health applications," Journal of Telemedicine and Telecare, vol. 18 , no. 5, pp. 273-281, 2012.

[7] M. C. Gibbons, R. F. Wilson, L. Samal et al., "Impact of consumer health informatics applications," Evidence Report/Technology Assessment, no. 188, pp. 1-546, 2009.

[8] D. L. G. Borzekowski, J. Leith, D. R. Medoff et al., "Use of the internet and other media for health information among clinic outpatients with serious mental illness," Psychiatric Services, vol. 60, no. 9, pp. 1265-1268, 2009.

[9] S. Clayton, D. Borzekowski, S. Himelhoch et al., "Media and internet ownership and use among mental health outpatients with serious mental illness," The American Journal of Drug and Alcohol Abuse, vol. 35, no. 5, pp. 364-367, 2009.

[10] D. Gandhi, C. Welsh, M. Bennett, J. Carreño, and S. Himelhoch, "Acceptability of technology-based methods substance abuse counseling in office based buprenorphine maintenance for opioid dependence," American Journal on Addictions, vol. 18, no. 2, pp. 182-183, 2009.

[11] S. Himelhoch, D. Mohr, J. Maxfield et al., "Feasibility of telephone-based cognitive behavioral therapy targeting major depression among urban dwelling African-American people with co-occurring HIV,' Psychology, Health and Medicine, vol. 16, no. 2, pp. 156-165, 2011.

[12] K. E. Heron and J. M. Smyth, "Ecological momentary interventions: incorporating mobile technology into psychosocial and health behaviour treatments," British Journal of Health Psychology, vol. 15, part 1, pp. 1-39, 2010.

[13] S. Krishna, S. A. Boren, and E. A. Balas, "Healthcare via cell phones: a systematic review," Telemedicine and e-Health, vol. 15, no. 3, pp. 231-240, 2009.

[14] H. Cole-Lewis and T. Kershaw, "Text messaging as a tool for behavior change in disease prevention and management," Epidemiologic Reviews, vol. 32, no. 1, pp. 56-69, 2010.

[15] B. S. Fjeldsoe, A. L. Marshall, and Y. D. Miller, "Behavior change interventions delivered by mobile telephone short-message service," American Journal of Preventive Medicine, vol. 36, no. 2, pp. 165-173, 2009.

[16] N. Dowshen, L. M. Kuhns, A. Johnson, B. J. Holoyda, and R. Garofalo, "Improving adherence to antiretroviral therapy for youth living with HIV/AIDS: a pilot study using personalized, 
interactive, daily text message reminders," Journal of Medical Internet Research, vol. 14, no. 2, article e51, 2012.

[17] H. Hardy, V. Kumar, G. Doros et al., "Randomized controlled trial of a personalized cellular phone reminder system to enhance adherence to antiretroviral therapy," AIDS Patient Care and STDs, vol. 25, no. 3, pp. 153-161, 2011.

[18] M. A. Lewis, J. D. Uhrig, C. M. Bann et al., "Tailored text messaging intervention for HIV adherence: a proof-of-concept study," Health Psychology, vol. 32, no. 3, pp. 248-253, 2013.

[19] T. F. Page, K. J. Horvath, G. P. Danilenko, and M. Williams, "A cost analysis of an internet based medication adherence intervention for people living with HIV," JAIDS Journal of Acquired Immune Deficiency Syndromes, vol. 60, no. 1, pp. 1-4, 2012.

[20] J. L. Browna, P. A. Vanableb, M. P. Careyb, and L. Elinc, "Computerized stress management training for HIV+ women: a pilot intervention study," AIDS Care, vol. 23, no. 12, pp. 1525-1532, 2011.

[21] J. D. Fisher, K. R. Amico, W. A. Fisher et al., "Computer-based intervention in HIV clinical care setting improves antiretroviral adherence: the lifewindows project," AIDS and Behavior, vol. 15, no. 8, pp. 1635-1646, 2011.

[22] E. Aharonovich, E. Greenstein, A. O'Leary, B. Johnston, S. G. Seol, and D. S. Hasin, "HealthCall: technology-based extension of motivational interviewing to reduce non-injection drug use in HIV primary care patients-a pilot study," AIDS Care, vol. 24, no. 12, pp. 1461-1469, 2012.

[23] W. N. Gray, D. M. Janicke, E. B. Fennell, D. C. Driscoll, and R. M. Lawrence, "Piloting behavioral family systems therapy to improve adherence among adolescents with HIV: a case series intervention study," Journal of Health Psychology, vol. 16, no. 5, pp. 828-842, 2011.

[24] S. C. Kalichman, M. O. Kalichman, C. Cherry et al., "Brief behavioral self-regulation counseling for HIV treatment adherence delivered by cell phone: an initial test of concept trial," AIDS Patient Care and STDs, vol. 25, no. 5, pp. 303-310, 2011.

[25] T. M. da Costa, B. J. P. Barbosa, D. A. G. e Costa et al., "Results of a randomized controlled trial to assess the effects of a mobile SMS-based intervention on treatment adherence in HIV/AIDSinfected Brazilian women and impressions and satisfaction with respect to incoming messages," International Journal of Medical Informatics, vol. 81, no. 4, pp. 257-269, 2012.

[26] C. Pop-Eleches, H. Thirumurthy, J. P. Habyarimana et al., "Mobile phone technologies improve adherence to antiretroviral treatment in a resource-limited setting: a randomized controlled trial of text message reminders," AIDS, vol. 25, no. 6, pp. 825-834, 2011.

[27] J. M. Simoni, D. Huh, P. A. Frick et al., "Peer support and pager messaging to promote antiretroviral modifying therapy in seattle: a randomized controlled trial," Journal of Acquired Immune Deficiency Syndromes, vol. 52, no. 4, pp. 465-473, 2009.

[28] S. B. Mannheimer, R. Mukherjee, L. R. Hirschhorn et al., "The CASE adherence index: a novel method for measuring adherence to antiretroviral therapy," AIDS Care, vol. 18, no. 7, pp. 853-861, 2006.

[29] M. A. Chesney, J. R. Ickovics, D. B. Chambers et al., "Selfreported adherence to antiretroviral medications among participants in HIV clinical trials: the AACTG Adherence Instruments," AIDS Care, vol. 12, no. 3, pp. 255-266, 2000.

[30] M. Duggan and L. Rainie, Cell Phone Activities, Pew Research Center's Internet \& American Life Project, Washington, DC,
USA, 2012, http://pewinternet.org/ /media//Files/Reports/ 2012/PIP_CellActivities_11.25.pdf.

[31] K. C. M. Bahadur and P. J. Murray, "Cell phone short messaging service (SMS) for HIV/AIDS in South Africa: a literature review," Studies in Health Technology and Informatics, vol. 160, part 1, pp. 530-534, 2010.

[32] T. Horvath, H. Azman, G. E. Kennedy, and G. W. Rutherford, "Mobile phone text messaging for promoting adherence to antiretroviral therapy in patients with HIV infection," Cochrane Database of Systematic Reviews, no. 3, Article ID CD009756, 2012.

[33] R. T. Lester, P. Ritvo, E. J. Mills et al., "Effects of a mobile phone short message service on antiretroviral treatment adherence in Kenya (WelTel Kenya1): a randomised trial," The Lancet, vol. 376, no. 9755, pp. 1838-1845, 2010.

[34] K. Sidney, J. Antony, R. Rodrigues et al., "Supporting patient adherence to antiretrovirals using mobile phone reminders: patient responses from South India," AIDS Care, vol. 24, no. 5, pp. 612-617, 2012.

[35] M. Bachhuber, W. B. Bilker, H. Wang, J. Chapman, and R. Gross, "Is antiretroviral therapy adherence substantially worse on weekends than weekdays?" Journal of Acquired Immune Deficiency Syndromes, vol. 54, no. 1, pp. 109-110, 2010.

[36] D. Skinner, U. Rivette, and C. Bloomberg, "Evaluation of use of cellphones to aid compliance with drug therapy for HIV patients," AIDS Care, vol. 19, no. 5, pp. 605-607, 2007.

[37] W. H. Curioso and A. E. Kurth, "Access, use and perceptions regarding Internet, cell phones and PDAs as a means for health promotion for people living with HIV in Peru," BMC Medical Informatics and Decision Making, vol. 7, article 24, 2007.

[38] W. H. Curioso, D. A. Quistberg, R. Cabello et al., "'It's time for your life': how should we remind patients to take medicines using short text messages?" AMIA Annual Symposium Proceedings, vol. 2009, pp. 129-133, 2009. 


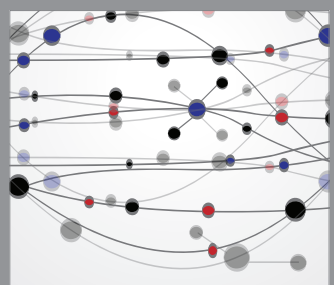

The Scientific World Journal
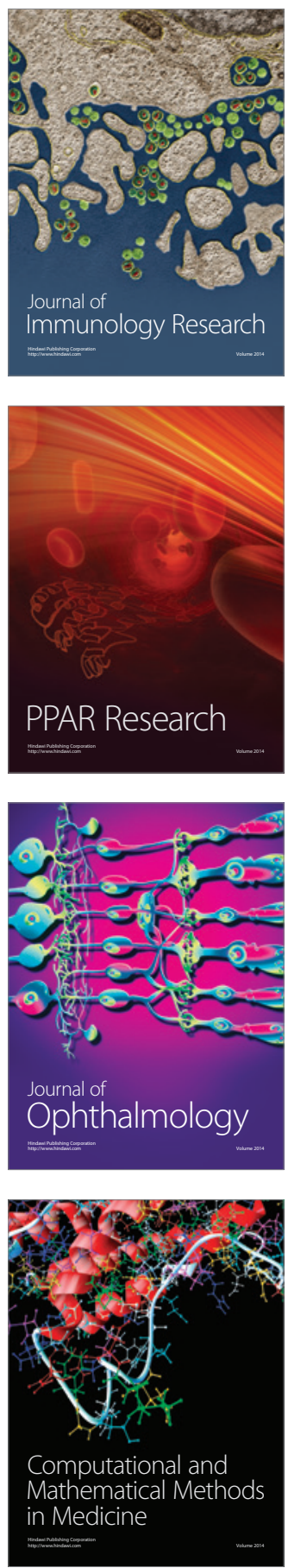

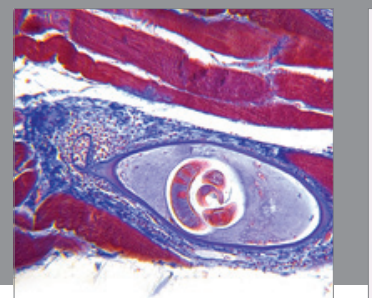

Gastroenterology

Research and Practice
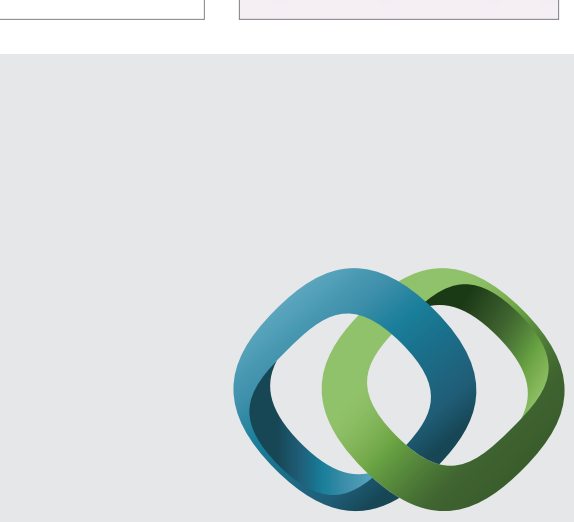

\section{Hindawi}

Submit your manuscripts at

http://www.hindawi.com
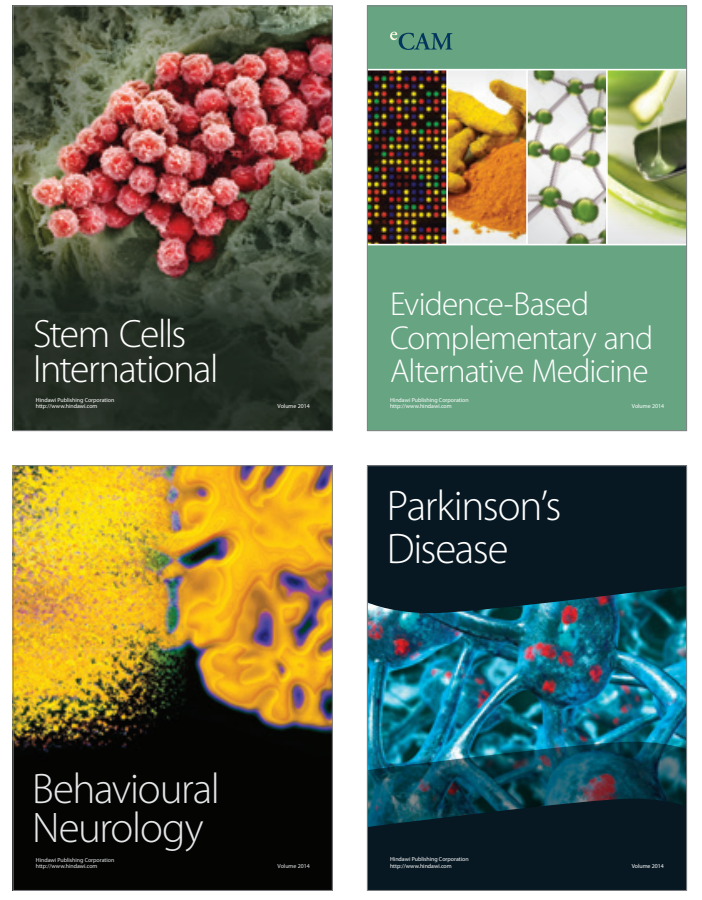
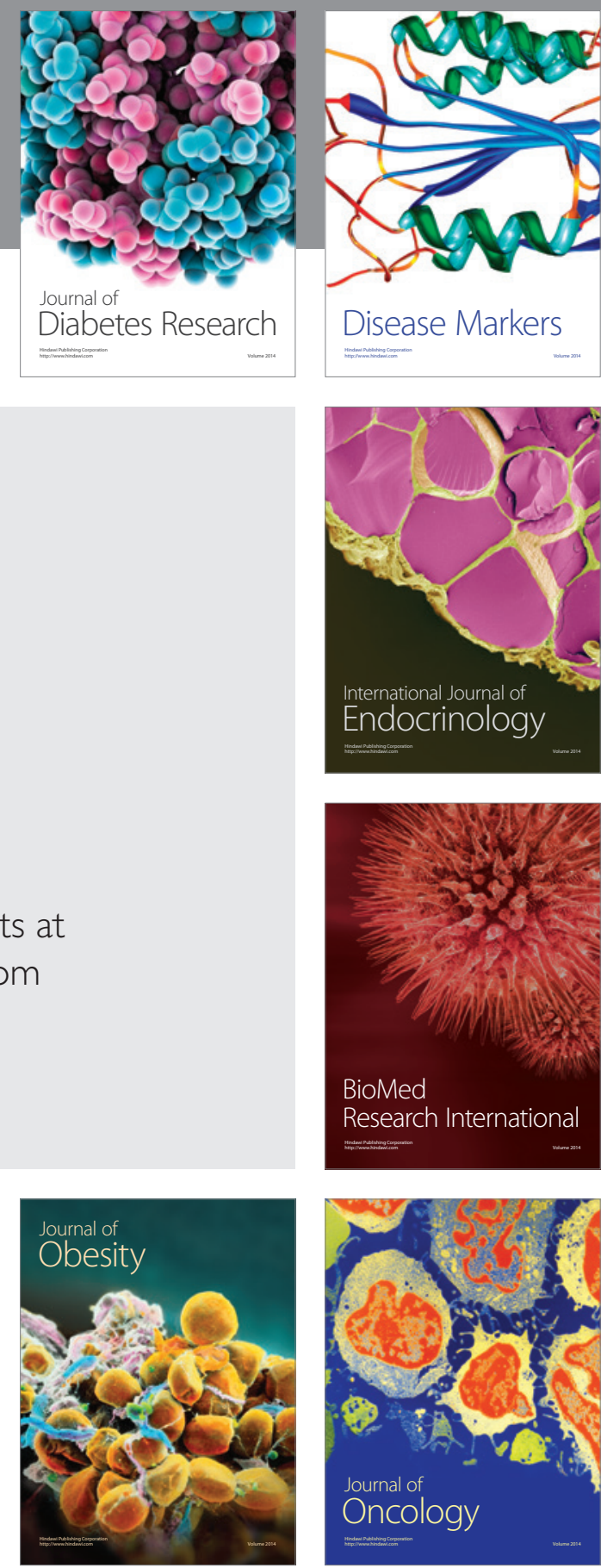

Disease Markers
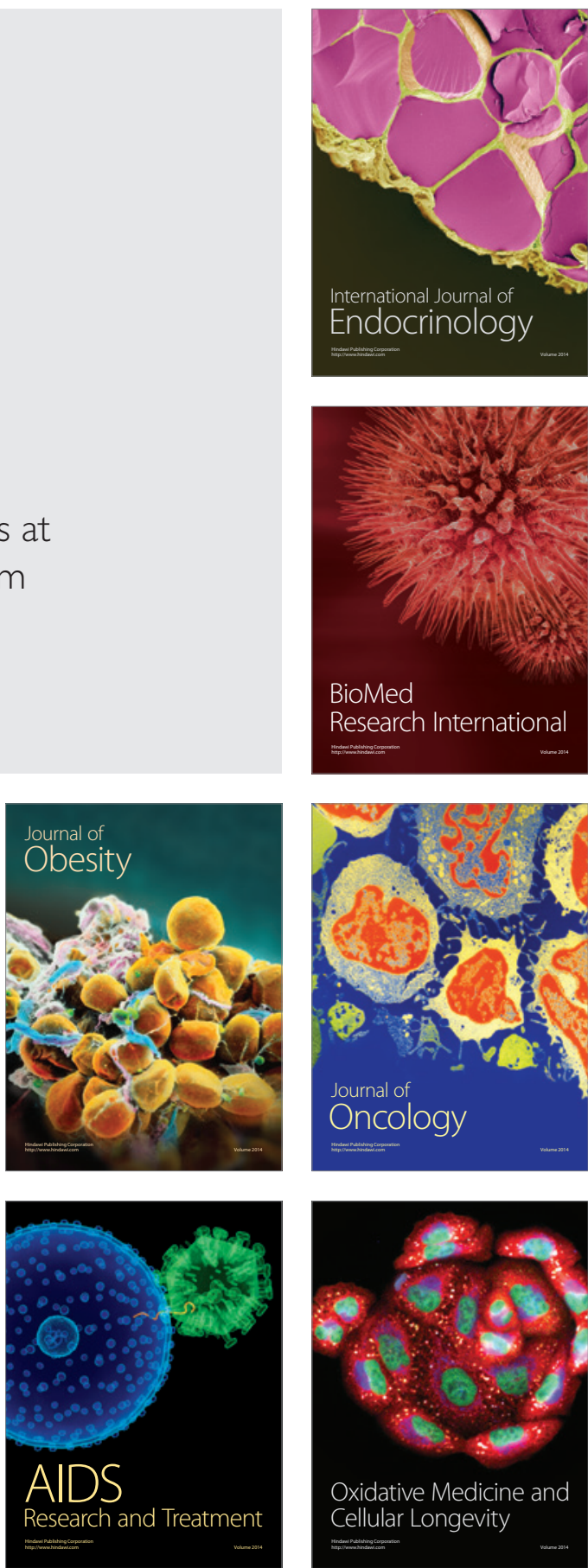